Zoonotic virus

A virus that normally exists in vertebrate animals, but can also be transmitted to humans and can cause disease in both animals and humans.

* Lindsley F. Kimball Research Institute, New York Blood Center, 310 East 67th Street, New York, New York 10065 USA.

₹State Key Laboratory of Pathogen and Biosecurity, Beijing Institute of Microbiology and Epidemiology, Beijing 100071, China. §School of Pharmaceutical Sciences, Southern Medical University, Guangzhou 510515, China. "Department of Microbiology, University of Hong Kong, Pokfulam, Hong Kong SAR, China. Correspondence to S.J. e-mail: sjiang@ nybloodcenter.org doi:10.1038/nrmicro2090 Published online 9 February 2009

\title{
The spike protein of SARS-CoV - a target for vaccine and therapeutic development
}

\author{
Lanying Du*, Yuxian He*, Yusen Zhou ${ }^{\ddagger}$, Shuwen Liu§, Bo-Jian Zhengl| and \\ Shibo Jiang*
}

Abstract | Severe acute respiratory syndrome (SARS) is a newly emerging infectious disease caused by a novel coronavirus, SARS-coronavirus (SARS-CoV). The SARS-CoV spike (S) protein is composed of two subunits; the $\mathrm{S} 1$ subunit contains a receptor-binding domain that engages with the host cell receptor angiotensin-converting enzyme 2 and the $\mathrm{S} 2$ subunit mediates fusion between the viral and host cell membranes. The $\mathrm{S}$ protein plays key parts in the induction of neutralizing-antibody and T-cell responses, as well as protective immunity, during infection with SARS-CoV. In this Review, we highlight recent advances in the development of vaccines and therapeutics based on the $\mathrm{S}$ protein.

Severe acute respiratory syndrome (SARS) was the first new infectious disease identified in the twenty-first century. This acute, and often severe, respiratory illness originated in the Guangdong province of China in November 2002 (REF. 1). A global effort coordinated by WHO led to the identification, in April 2003, of a new coronavirus, SARS-coronavirus (SARS-CoV), as the agent that caused the outbreak ${ }^{2}$.

SARS-CoV is an enveloped, single and positivestranded RNA virus ${ }^{2}$. Its genome RNA encodes a nonstructural replicase polyprotein and structural proteins, including spike (S), envelope (E), membrane $(\underline{M})$ and nucleocapsid (N) proteins ${ }^{3-5}$. SARS-CoV, a zoonotic virus, resides in hosts that form its natural reservoir, such as bats, but can also infect intermediate hosts, such as small animals (for example, palm civets), before being transmitted to humans $s^{6-8}$. SARS-CoV can infect and replicate in several cell types in the human body and causes serious pathological changes (BOX 1, FIG 1). A further understanding of the life cycle and pathogenesis of SARS-CoV will help us to develop vaccines and therapeutics to prevent and treat SARS-CoV and SARS-like coronavirus (SL-CoV) infections in the future.

After its first occurrence, SARS rapidly spread around the world along international air-travel routes, reaching all five continents and 29 countries, resulting in 8,098 cases and 774 deaths by 23 September 2003 (REF. 9). The overall fatality of SARS is about $10 \%$ in the general population, but $>50 \%$ in patients aged 65 years and older (WHO update 49; see Further information). The global outbreak of SARS was brought under control in July 2003 by effective quarantine, patient-isolation and travel restrictions. Four sporadic SARS cases caused by different SARS-CoV isolates than those that predominated in the 2002-2003 outbreak were reported in late 2003 and early 2004 (REFS 10-12). The most recent epidemic of SARS occurred in Beijing and Anhui in China in April 2004 and originated from laboratory contamination (WHO update 7; see Further information). Since then, no new case of SARS has been reported, possibly because of continued global vigilance and surveillance and laboratory bio-safety practices, as well as the euthanizing or quarantining of animals that may have been exposed to SARS-CoV ${ }^{13,14}$. Although the outbreaks of SARS seem to be over, SARS is still a safety concern because of the possible reintroduction of a SL-CoV into humans and the risk of an escape of SARS-CoV from laboratories ${ }^{15,16}$.

Infection with SARS-CoV can trigger a series of humoral and cellular immune responses. Specific antibodies against SARS-CoV (immunoglobulin G (IgG) and $\operatorname{IgM}$ ) were detectable approximately 2 weeks postinfection, reaching a peak 60 days post-infection and remaining at high levels until 180 days post-infection (REF. 17). High titres of neutralizing antibodies and SARS$\mathrm{CoV}$-specific cytotoxic $\mathrm{T}$ lymphocyte responses were detected in patients who had recovered from SARS ${ }^{18,19}$, and the levels of the responses correlated well with the disease outcome $\mathrm{e}^{20}$. This suggests that both humoral and cellular immune responses are crucial for the clearance of infection by SARS-CoV. 


\section{Box 1 | Pathology of SARS and the life cycle of SARS-CoV infection}

Severe acute respiratory syndrome-coronavirus (SARS-CoV) spreads primarily through droplets (respiratory secretions) and close person-to-person contact. After the virus enters into the body, it binds to primary target cells that express abundant virus receptor, the angiotensin-converting enzyme 2 (ACE2), including pneumocytes and enterocytes in the respiratory system. The virus enters and replicates in these cells. The matured virions are then released to infect new target cells ${ }^{121}$ (FIG. 1). SARS-CoV can also infect mucosal cells of intestines, tubular epithelial cells of kidneys, epithelial cells of renal tubules, cerebral neurons and immune cells ${ }^{122,123}$. Infectious viral particles in patients with SARS can be excreted through respiratory secretions, stool, urine and sweat. SARS-CoV infection damages lung tissues owing to elevated levels of production and activation of proinflammatory chemokines and cytokines ${ }^{124}$, resulting in atypical pneumonia with rapid respiratory deterioration and failure.

Neutralizing antibodies and/or T-cell immune responses can be raised directly against several SARS$\mathrm{CoV}$ proteins ${ }^{21-23}$, but mainly target the $\mathrm{S}$ protein ${ }^{20,24-26}$, suggesting that $\mathrm{S}$ protein-induced specific immune responses play important parts in the fight against SARS-CoV infection ${ }^{18}$. SARS-CoV S protein also has a key role in the ability of SARS-CoV to overcome the species barrier, as adaptive evolution of S protein can contribute to the animal-to-human transmission of SARS$\mathrm{CoV}^{27}$. Because the $\mathrm{S}$ protein of SARS-CoV is involved in receptor recognition, as well as virus attachment and entry, it represents one of the most important targets for the development of SARS vaccines and therapeutics.

\section{Structure of the SARS-CoV S protein}

The spikes of SARS-CoV are composed of trimers of $S$ protein, which belongs to a group of class I viral fusion glycoproteins that also includes HIV glycoprotein 160 (Env), influenza haemagglutinin (HA), paramyxovirus $\mathrm{F}$ and Ebola virus glycoprotein ${ }^{28}$. The SARS-CoV S protein encodes a surface glycoprotein precursor that is predicted to be 1,255 amino acids in length, and the amino terminus and most of the protein is predicted to be on the outside of the cell surface or the virus particles ${ }^{3}$. The predicted $S$ protein consists of a signal peptide (amino acids 1-12) located at the $\mathrm{N}$ terminus, an extracellular domain (amino acids 13-1,195), a transmembrane domain (amino acids 1,196-1,215) and an intracellular domain (amino acids 1,216-1,255) ${ }^{29-32}$ (FIG. 2a). Similarly to other coronaviruses, the S protein of SARS-CoV can be cleaved into the S1 and S2 subunits by proteases, such as trypsin ${ }^{33}$, factor $\mathrm{Xa}^{34}$ and cathep$\sin \mathrm{L}^{35}$. The trypsin cleavage site occurs at R667-S668 (REF. 36), whereas cathepsin L cleavage is mapped to T678-M679 in the S protein ${ }^{35}$. Cathepsin L cleaves the $S$ protein of SARS-CoV upstream of, rather than adjacent to, the fusion peptide, and the cleavage is required for activation of the membrane fusion domain of the $S$ protein following entry into target cell ${ }^{35}$.

Angiotensin-converting enzyme 2 (ACE2) has been

Adaptive evolution
A process that enables living organisms to cope with environmental stresses and pressures for survival in a new host. For example, under positive selective pressure civet SARS-CoV can evolve and subsequently adapt to the human host.
$\mathrm{N}$ terminus of the receptor peptidase, on which amino acids 445-460 anchor the entire receptor-binding loop of the RBD core (FIG. 2b). This loop (amino acids 424494 of the RBD), which makes complete contact with the receptor ACE2, was referred to as receptor-binding motif (RBM) (FIG. 2a). The RBM region is tyrosine rich. Among the 14 residues of RBM that are in direct contact with ACE2, six are tyrosine, representing both the hydroxyl group and hydrophobic ring. The RBD region also contains multiple cysteine residues that are linked by disulphide bonds ${ }^{29}$ (FIG. 2c). Two residues in particular, those at positions 479 and 487, determine SARS disease progression and SARS-CoV tropism (host range ${ }^{41,42}$. Any residue changes in these two positions might therefore enhance animal-to-human or human-to-human transmission ${ }^{29}$.

Human and animal SARS-CoVs depend on ACE2 for cell entry. Animal SARS-CoV could evolve to infect humans by a series of transmission events between animals and humans. For example, a chimeric recombinant SARS-CoV that bears the S protein of civet SARS-CoV (icSZ16-S) can adapt to human airway epithelial cells and displays enhanced affinity for human ACE2 (REF. 43). Changes of only a few residues in the RBD of the civet SARS-CoV S protein, which is responsible for binding with the peptidase domain of ACE2, result in enhanced human ACE2-binding affinity of SARS-CoVs from animals, including civets, mice and rats, facilitating efficient cross-species infections ${ }^{29}$. However, the SL-CoV from bats does not infect ACE2-expressing cells ${ }^{78}$, suggesting that, unlike SARS-CoVs from human and civets, the SL-CoV from bats does not use ACE2 as a cellular receptor. Thus, the SL-CoV from bats might be the precursor of animal SARS-CoVs, which may act as the intermediates for animal-to-human transmission.

\section{Functions of the SARS-CoV S protein}

SARS-CoV S protein has pivotal roles in viral infection and pathogenesis ${ }^{44,45}$. S1 recognizes and binds to host receptors, and subsequent conformational changes in S2 facilitate fusion between the viral envelope and the host cell membrane $e^{30,33}$.

Receptor binding. The RBD in $\mathrm{S} 1$ is responsible for virus binding to host cell receptors ${ }^{30,37,39}$. ACE2 from SARS-CoV-permissive Vero E6 cells efficiently binds S1, and its soluble form blocks S1 from associating with Vero E6 cells. In addition, SARS-CoV replicates efficiently in ACE2-transfected cells, and anti-ACE2 antibodies block virus entry and replication in Vero E6 cells. This shows that ACE2 is a functional receptor for SARS-CoV ${ }^{37,46,47}$. A total of 18 residues of ACE2 keep contact with 14 amino acids in the RBD of SARSCoV S protein ${ }^{29}$. K341 of ACE2 and R453 of the RBD are important for the complex formation ${ }^{48}$. N479 and T487 of the RBD are important for the high-affinity association of S protein with ACE2 (REF. 42). A point mutation at R441 or D454 of the RBD disrupts the antigenic structure and binding activity of RBD to ACE2 (REFS 30,49). 


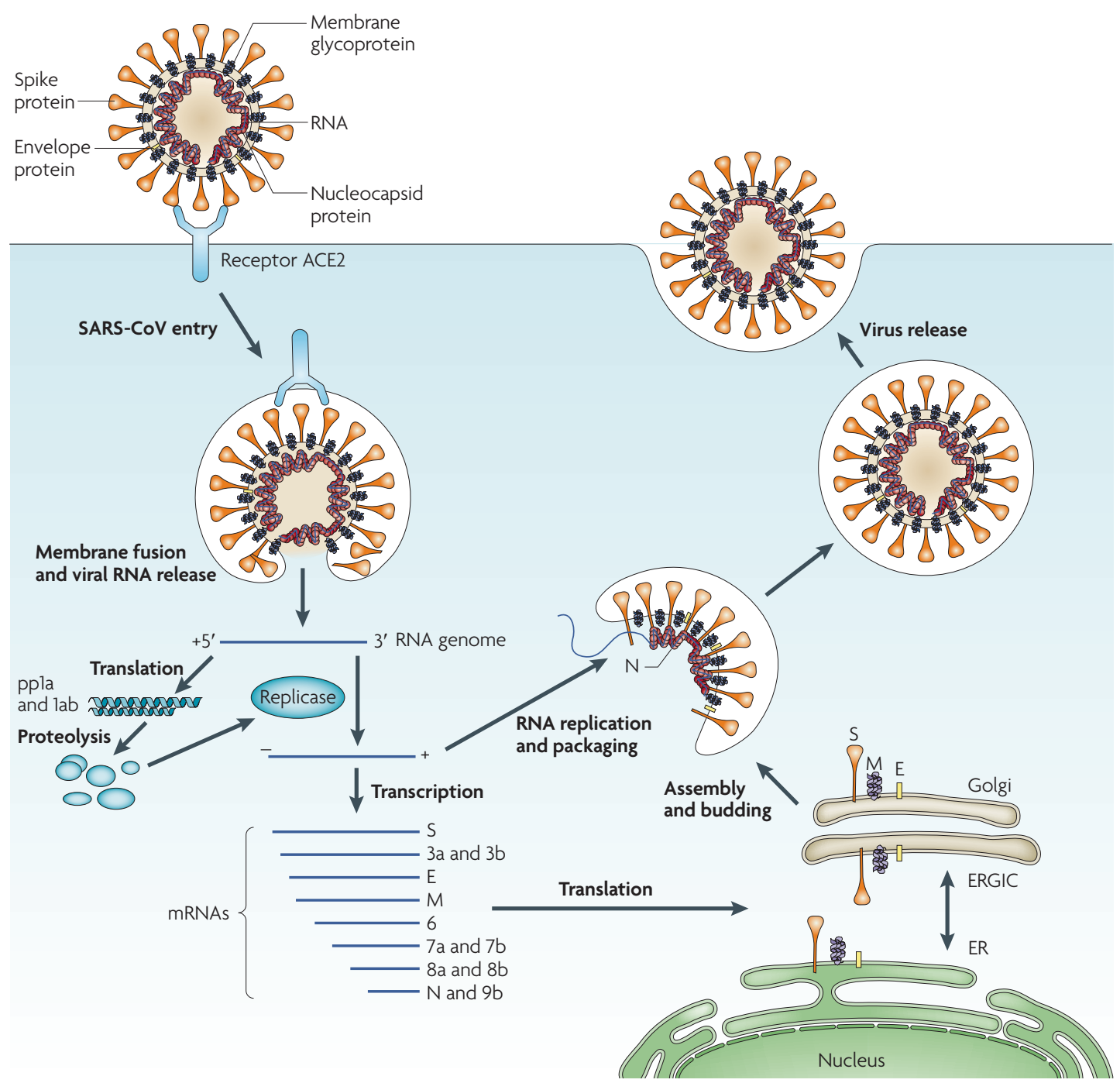

Figure 1 | The life cycle of SARS-CoV in host cells. Severe acute respiratory syndrome-coronavirus (SARS-CoV) enters target cells through an endosomal pathway ${ }^{113,121,125-127}$. S protein first binds to the cellular receptor angiotensin-converting enzyme 2 (ACE2) ${ }^{129}$, and the ACE2-virus complex is then translocated to endosomes, where S protein is cleaved by the endosomal acid proteases (cathepsin $\mathrm{L}$ ) ${ }^{105}$ to activate its fusion activity. The viral genome is released and translated into viral replicase polyproteins pp1a and 1ab, which are then cleaved into small products by viral proteinases. Subgenomic negative-strand templates are synthesized from discontinuous transcription on the plus-strand genome and serve as templates for mRNA synthesis. The full-length negative-strand template is made as a template for genomic RNA. Viral nucleocapsids are assembled from genomic RNA and N protein in the cytoplasm, followed by budding into the lumen of the ERGIC (endoplasmic reticulum (ER)-Golgi intermediate compartment) ${ }^{128}$. Virions are then released from the cell through exocytosis.

SARS-CoV can also bind to host cells through alternative receptors, such as DC-SIGN (dendritic cellspecific intercellular adhesion molecule-3-grabbing non-integrin) and/or L-SIGN (liver/lymph nodeSIGN) $)^{50,51}$. Seven asparagine-linked glycosylation sites in the S protein, including residues at positions 109, 118, $119,158,227,589$ and 699, are crucial for DC-SIGNor L-SIGN-mediated virus entry. These residues differ from those of the ACE2-binding domain located at amino acids $318-510$ (REF. 52). This would suggest that $S$ protein can also use DC-SIGN or L-SIGN as a receptor, independently of ACE2. However, the actual function of DC-SIGN and L-SIGN needs to be further verified.
Viral fusion. The fusion process that is mediated by $S$ protein of SARS-CoV is similar to that mediated by class I viral fusion proteins of other viruses, such as HIV-1 and murine hepatitis virus (MHV) $)^{53,54}$, but may occur in the acidic environment of the endosomes, rather than on the cell surface. S2 contains heptad repeat 1 (HR1) and HR2 domains, which play an important part in SARS-CoV fusion with target cells. Binding of the RBD of $\mathrm{S} 1$ to the receptor ACE2 triggers a conformational change of the S2 from a pre-fusion form to a post-fusion form, resulting in insertion of the putative fusion peptide (amino acids 770-788) ) $^{31}$ into the target cell membrane and association of HR1 

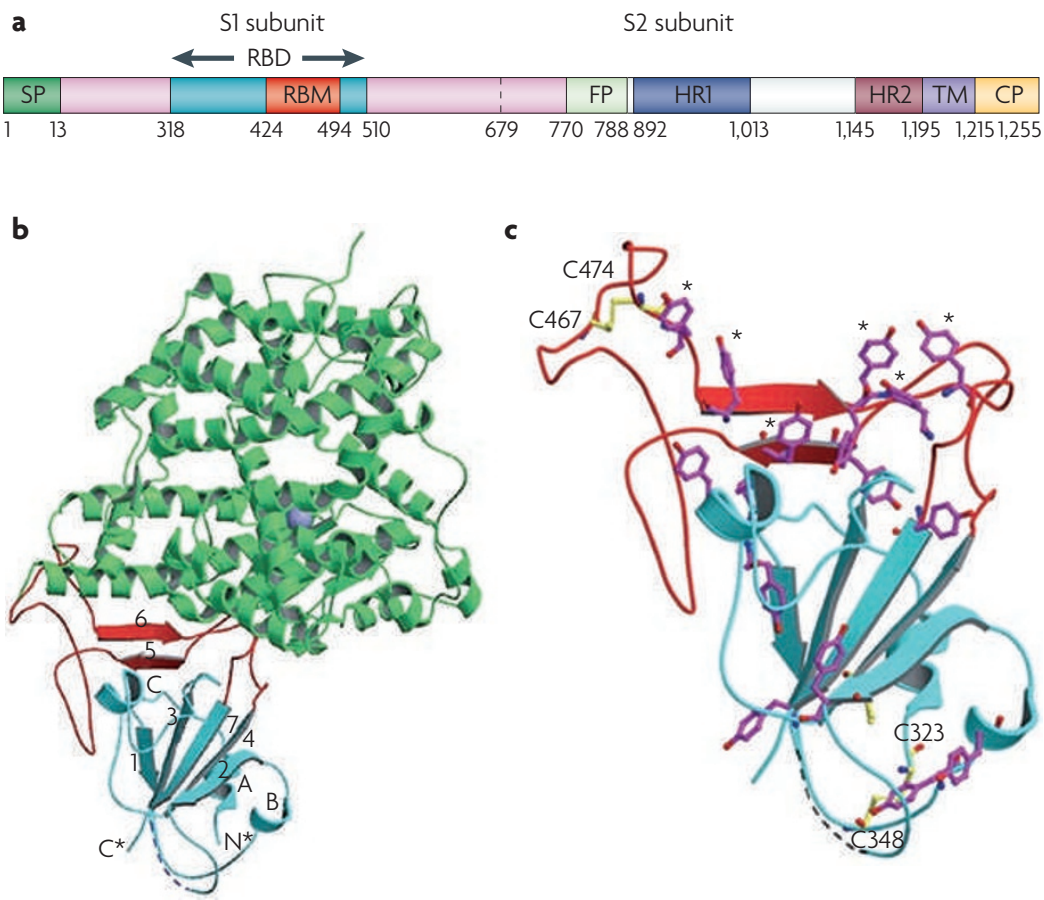

Figure 2 | SARS-CoV S protein structure and its complex with the receptor ACE2. a Schematic of the $S$ protein ${ }^{29-32}$. The residue numbers of each region represent their positions in the $\mathrm{S}$ protein of severe acute respiratory syndrome-coronavirus (SARS-CoV). b |Crystal structures of the RBD complexed with the receptor. RBD (the core structure is cyan and the loop RBM is red) interacts with the receptor angiotensin-converting enzyme 2 (ACE2; green). A five-stranded anti-parallel $\beta$-sheet ( $\beta 1-\beta 4$ and $\beta 7$ ) that connects with three short $\alpha$-helices $(\alpha \mathrm{A}-\alpha \mathrm{C})$ constitutes the core, whereas a two-stranded $\beta$-sheet ( $\beta 5$ and $\beta 6$ ) forms the loop. $N^{*}$ and $C^{*}$ represent the amino and carboxyl termini of the RBD, respectively. $\mathbf{c}$ | The RBD tyrosine (magenta) and cysteine (yellow) residue distribution ${ }^{29}$. The asterisks represent six ACE2-contacting tyrosines on the RBD, and two disulphide bonds are shown to link C323 to C348 and C467 to C474. CP, cytoplasm domain; FP, fusion peptide; HR, heptad repeat; RBD, receptor-binding domain; RBM, receptor-binding motif; SP, signal peptide; TM, transmembrane domain. Parts b and $\mathbf{c}$ are adapted, with permission, from REF. 29 (C) (2005) American Association for the Advancement of Science.

SARS pseudovirus A synthetic virus that bears the SARS-CoV S protein and contains an Env-defective, luciferase-expressing genome of a retrovirus (for example, HIV), and can infect but does not replicate in cells that express receptors for SARS-CoV. and HR2 domains to form a six-helix bundle fusion core structure. This brings the viral envelope and target cell membrane into close proximity for fusion. The crystal structure of the SARS-CoV fusion core is described in detail in REF. 55 (FIG. 3). Similarly to the $S$ protein of MHV, but not gp41 of HIV-1, SARS-CoV S protein has a longer HR1 region than HR2 region. The six-helix bundle fusion core has a rod-shaped structure with a length of $\sim 70 \AA$ and a diameter of $\sim 28 \AA$. Three HR1 helices form a parallel trimeric coiled-coil that is surrounded by three HR2 helices in an oblique, antiparallel manner ${ }^{55}$ (FIG. 3). A synthetic peptide derived from the HR2 region could interact with an HR1 peptide to form a stable six-helix bundle and inhibit SARS-CoV infection in a dose-dependent manner ${ }^{53}$. Consequently, both the HR1 and HR2 regions in the S2 domains are expected to participate in the viral fusion and entry processes and will serve as attractive targets for the development of anti-SARS-CoV therapeutics and vaccines.

\section{Vaccines based on the SARS-CoV S protein}

The roles of S protein in receptor binding and membrane fusion indicate that vaccines based on the S protein could induce antibodies to block virus binding and fusion or neutralize virus infection. Among all structural proteins of SARS-CoV, S protein is the main antigenic component that is responsible for inducing host immune responses, neutralizing antibodies and/or protective immunity against virus infection. S protein has therefore been selected as an important target for vaccine and antiviral development. A comparison of these approaches is provided in TABLE 1.

It has been reported that antibodies raised to amino acids 485-625 in S1 or 1,029-1,192 in S2 neutralize infection by SARS-CoV strains (for example, Tor2 and Sin2774) in Vero E6 cells ${ }^{56,57}$. Vaccination of African green monkeys with an attenuated parainfluenza virus that encodes the full-length S protein of SARS-CoV Urbani strain resulted in the production of $S$ proteinspecific neutralizing antibodies, which protected vaccinated monkeys from subsequent homologous SARS-CoV challenge ${ }^{58}$, suggesting that immunization with the S protein of SARS-CoV is highly effective in the prevention of SARS.

Vaccines based on the full-length S protein. Several vaccines that are based on the full-length $S$ protein of SARS$\mathrm{CoV}$ have been reported. Yang et al..$^{59}$ showed that a DNA vaccine encoding the full-length S protein SARS-CoV Urbani strain could induce both T-cell and neutralizingantibody responses, as well as protective immunity, in a mouse model. Other groups have also shown that vaccination of mice or monkeys with highly attenuated modified vaccinia virus Ankara (MVA), which encodes the full-length S protein of the SARS-CoV Urbani strain or HKU39849 strain, elicited S-specific neutralizing antibodies and protective immunity, as evidenced by decreased virus titres in the respiratory tracts of animals after homologous SARS-CoV challenge ${ }^{60,61}$. Passive transfer of murine serum to naive mice also protected these mice from the challenge of homologous SARS-CoV ${ }^{60,61}$. In addition, vaccination of mice or hamsters with a full-length $S$ protein trimer protected these animals from infection by homologous SARS-CoV (HKU39849 strain) ${ }^{62}$. Furthermore, a recombinant baculovirus-expressed full-length $S$ protein of the Urbani strain and its trimer could induce sufficient neutralizing antibodies against human and palm civet SARS pseudoviruses that bore $\mathrm{S}$ proteins of homologous and heterologous SARS-CoV variants (for example, Tor2, GD03T13 and SZ3 strains) in vaccinated mice ${ }^{63}$. These reports suggest that the full-length $S$ protein is highly immunogenic and induces protection against SARS-CoV challenge and that neutralizing antibodies alone may be able to suppress virus proliferation, further justifying the rationale that vaccines can be developed based on the $S$ protein.

Although full-length S protein-based SARS vaccines can induce neutralizing antibody responses against SARS-CoV infection, they may also induce harmful immune responses that cause liver damage of the vaccinated animals or enhanced infection after challenge with 
a

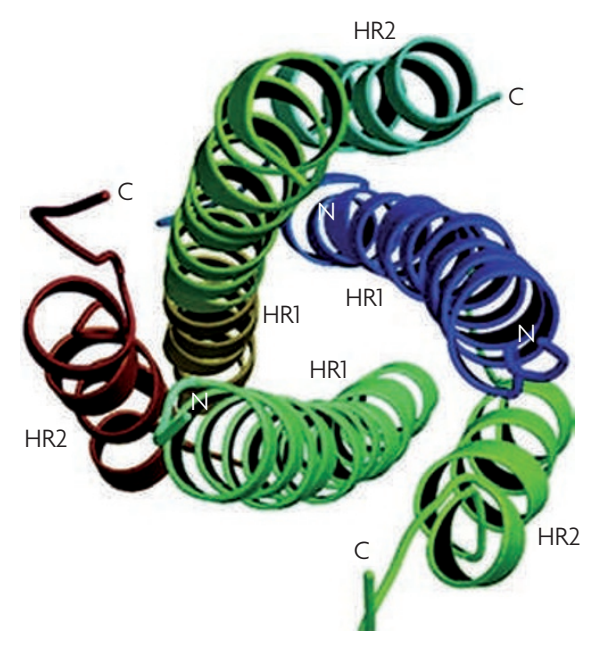

b

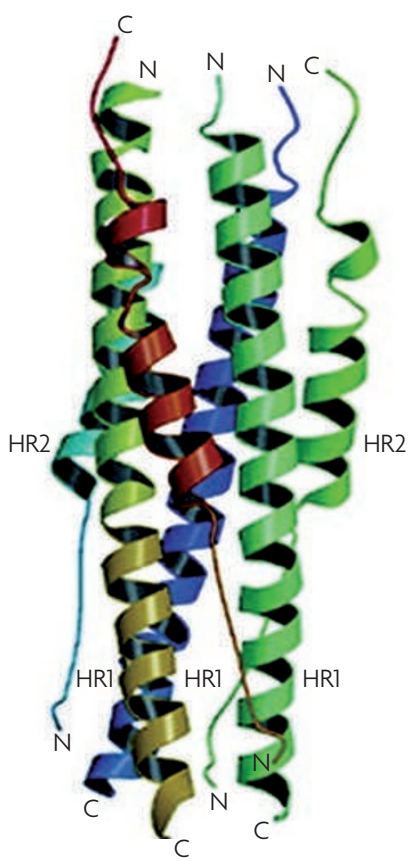

Figure $3 \mid$ The fusion core structure. The fusion core is a six-helix bundle with three HR2 $\alpha$-helices packed in an oblique antiparallel manner against the hydrophobic grooves on the surface of the central HR1 trimer ${ }^{55,130}$. A top (a) and side (b) view is shown of the severe acute respiratory syndrome-coronavirus (SARS-CoV) S protein six-helix bundle fusion core structure formed by the HR1 and HR2 domains in the S2 subunit. C, carboxyl; $\mathrm{N}$, amino. Figure adapted, with permission, from REF. 55 (c) (2004) American Society for Biochemistry and Molecular Biology.

and heterologous SARS-CoV isolates, including the representative strains of human 2002-2003 and 2003-2004 SARS-CoV (Tor2 and GD03, respectively) and palm civet SARS-CoV $(\mathrm{SZ3})^{71}$. Immunization of mice with RBD-Fc induces long-term protective immunity against challenge with homologous SARS-CoV BJ01 strain ${ }^{70,72}$. Administration of an adeno-associated virus (AAV)based vaccine that contains RBD (RBD-rAAV) by intramuscular and mucosal pathways elicits sufficient neutralizing antibodies to inhibit homologous SARS$\mathrm{CoV}$ (GZ50) challenge in the established mouse model, and the immune responses can be enhanced by priming with RBD-rAAV and boosting with RBD-specific peptides $^{73-75}$.

The SARS-CoV S protein can also induce CD8 ${ }^{+}$ $\mathrm{T}$-cell responses. One H-2(b)- and one H-2(d)restricted T-cell epitope are mapped to RBD (S436-S443 and S366-S374, respectively) ${ }^{24}$. Immunization of mice with a RBD-based subunit vaccine (S318-S510) elicits both antibody and cellular immune responses against SARS-CoV ${ }^{26}$. The RBD of S protein contains multiple conformation-dependent epitopes and is the main domain that induces neutralizing antibody and T-cell immune responses against SARS-CoV infection ${ }^{76,77}$, making it an important target for vaccine development. The approaches for developing RBD-based vaccines against SARS-CoV have provided useful information for designing vaccines against other viruses with class I fusion proteins, as these proteins also contain RBDs in their S proteins.

It should be noted that the efficacy of these vaccine candidates is mainly tested in young-mouse and primate animal models. These models are usually less robust, providing virus replication but lacking clinical symptoms and diseases. It is necessary, therefore, to develop more-robust animal models of human diseases for evaluation of vaccine efficacy. Baric and colleagues ${ }^{78,79}$ have recently reported several lethal SARS-CoV challenge models in BALB/c mice that recapitulated the agerelated SARS disease by using recombinant SARS-CoV that bore the $S$ protein of early human and zoonotic strains (GZ02 and HC/SZ/61/03, respectively). They also developed another pathogenic model for young mice after 15 passages of the Urbani isolate in BALB/c mice, which resulted in a lethal virus, MA15, that replicates to high titres in the lungs of mice, causing clinical disease of SARS ${ }^{78,79}$. Other reports ${ }^{80,81}$ list examples for the use of senescent mouse models for vaccine evaluation. One candidate vaccine, Venezuelan equine encephalitis virus replicon particles, that expressed the Urbani SARS-CoV $S$ protein partially protected the aged mice from challenge with a recombinant heterologous SARS-CoV that bore epidemic and zoonotic S proteins (icGDO3-S), providing a model to mimic the age-related susceptibility observed in the elder population ${ }^{80}$. The animal models discussed above can be used as valuable tools to evaluate the efficacy of SARS vaccines.

\section{S protein-based therapeutics}

Peptides that interrupt the RBD-ACE2 interaction. It has been shown that rRBD blocks $S$ protein-mediated entry of lentivirus pseudotypes into ACE2-expressing 
Table 1 | S protein-based vaccines and antiviral therapies against SARS-CoV

\begin{tabular}{|c|c|c|c|}
\hline Category & Advantages & Disadvantages & Refs \\
\hline \multicolumn{4}{|l|}{ Vaccines* } \\
\hline Full-length S protein & $\begin{array}{l}\text { Induces effective neutralizing-antibody and T-cell responses, as } \\
\text { well as protective immunity }\end{array}$ & $\begin{array}{l}\text { Might induce harmful immune responses } \\
\text { that cause liver damage or enhanced } \\
\text { infection }\end{array}$ & 64,65 \\
\hline DNA-based & $\begin{array}{l}\text { Easier to design; induces immunoglobulin } \mathrm{G} \text {, neutralizing- } \\
\text { antibody and T-cell responses and/or protective immunity }\end{array}$ & $\begin{array}{l}\text { Might have low efficacy in humans; } \\
\text { repeated doses may cause toxicity }\end{array}$ & 59,131 \\
\hline $\begin{array}{l}\text { Recombinant S } \\
\text { protein-based }\end{array}$ & $\begin{array}{l}\text { Induces high neutralizing-antibody responses and protective } \\
\text { immunity }\end{array}$ & $\begin{array}{l}\text { Mainly humoral responses; need } \\
\text { repeated doses and adjuvants }\end{array}$ & 62 \\
\hline RBD & $\begin{array}{l}\text { Induces highly potent neutralizing-antibody and T-cell responses } \\
\text { and protective immunity }\end{array}$ & Not identified & $70-73$ \\
\hline DNA-based & $\begin{array}{l}\text { Induces neutralizing-antibody and T-cell responses and/or } \\
\text { protective immunity }\end{array}$ & $\begin{array}{l}\text { Induces low responses; might not } \\
\text { neutralize mutants }\end{array}$ & $132-134$ \\
\hline \multicolumn{4}{|l|}{ Therapeutics* } \\
\hline Peptides & $\begin{array}{l}\text { Inhibits virus infection by preventing S protein-mediated } \\
\text { receptor binding and blocking viral fusion and entry }\end{array}$ & Low antiviral potency & $\begin{array}{r}53,82-84 \\
136-138\end{array}$ \\
\hline RBD-ACE2 blockers & Blocks RBD-ACE2 binding and S protein-mediated infection & Not identified & 82,83 \\
\hline S cleavage inhibitors & Might interfere with S cleavage & Not identified & $84,136,137$ \\
\hline Fusion core blockers & Easy to design; inhibits virus infection with high specificity & Not identified & $53,89,90,138$ \\
\hline $\begin{array}{l}\text { Neutralizing } \\
\text { antibodies }\end{array}$ & $\begin{array}{l}\text { Highly potent virus inhibition and/or neutralization activity } \\
\text { against homologous and heterologous SARS-CoV isolates }\end{array}$ & $\begin{array}{l}\text { Might enhance SARS-CoV entry; further } \\
\text { studies needed }\end{array}$ & 139 \\
\hline Protease inhibitors & $\begin{array}{l}\text { Blocks virus entry and/or inhibits protease (cathepsin L) } \\
\text { proteolysis }\end{array}$ & Not identified & 103-105 \\
\hline S protein inhibitors & $\begin{array}{l}\text { Specifically inhibits S protein-mediated SARS-CoV fusion and } \\
\text { entry into the host cell }\end{array}$ & Not identified & 107-109 \\
\hline Small interfering RNAs & Reduces virus replication and/or silences $S$ gene expression & Low antiviral potency; limited usefulness & $113-117$ \\
\hline
\end{tabular}

*All candidates are at the preclinical study stage. ACE2, angiotensin-converting enzyme 2; ADE, antibody-dependent enhancement; HAMA, human-anti-mouse antibody, RBD, receptor-binding domain, SARS-CoV; severe acute respiratory syndrome-coronavirus.

293T cells with a half maximal inhibitory concentration $\left(\mathrm{IC}_{50}\right)$ of less than $10 \mathrm{nM}^{30}$. Similarly, a peptide that overlaps the RBD sequence (amino acids 471-503) blocks the RBD-ACE2 interaction, inhibiting SARS-CoV entry into Vero cells with an $\mathrm{IC}_{50}$ of approximately $40 \mu \mathrm{M}^{82}$. A polypeptide that contains two RBD-binding motifs of ACE2 (amino acids 22-44 and 351-357) linked by a glycine exhibits high potent inhibitory activity on SARS pseudovirus infection in ACE2-expressing HeLa cells with an $\mathrm{IC}_{50}$ of $100 \mathrm{nM}^{83}$. These findings suggest that peptides derived from both RBD and ACE2 that block RBD-ACE2 binding could be developed as novel therapeutics against SARS-CoV infection. However, the in vivo inhibitory activity of these peptides should be evaluated in animal models before considering further development.

Peptides that interfere with the cleavage of S protein. Cleavage of the $\mathrm{S}$ protein trimer is an important event in infection, making the potential cleavage site between S1 and S2 domains another target for development of anti-SARS-CoV agents. Synthetic peptides, including P6 (amino acids 598-617) and P8 (amino acids 737-756), both of which are close to the S1-S2 connection and cleavage site, exhibit potent inhibitory activity against the GZ50 strain of SARS-CoV infection in fetal rhesus kidney 
(FRhK4) cells, and have $\mathrm{IC}_{90}$ values of approximately 100 and $25 \mu \mathrm{M}^{84}$. This suggests that binding of the peptides to the $\mathrm{S}$ protein interferes with the cleavage of $\mathrm{S} 1$ and S2, inhibiting the production of functional S1 and S2 subunits and subsequent fusion of the viral envelope and the host cell membrane. Again, the in vivo antiviral efficacy of these peptides should be tested in animal models.

Peptides that block the HR1-HR2 interaction from forming a fusion-active core. In the early 1990s, Jiang et al..$^{85}$ and Wild et al. ${ }^{86}$ discovered the highly potent anti-HIV peptides derived from the HIV-1 gp41 HR2 region. One of the HR2 peptides, T20 (enfuvirtide), was approved by the US Food and Drug Administration for the treatment of patients with HIV or AIDS, especially those who have failed to respond to the current antiretroviral drugs. These HR2 peptides could interact with the viral gp41 HR1 region at fusion-intermediate conformation and block six-helix bundle formation, resulting in the inhibition of HIV fusion at the nanomolar level ${ }^{87,88}$. Because the SARS-CoV S protein S2 domain also contains HR1 and HR2 sequences, we anticipated that peptides derived from the HR2 region of the SARS-CoV S protein S2 domain would also have antiviral activity against SARS-CoV. We designed and synthesized several peptides that overlapped the HR2 sequence and found that one of these, designated CP-1, could interact with an HR1 peptide to form a stable six-helix bundle and inhibited infection by SARS-CoV WHU strain in Vero E6 cells with an $\mathrm{IC}_{50}$ of approximately $20 \mu \mathrm{M}^{53}$. Later, several other research groups also identified anti-SARS-CoV peptides from the S2 domain HR2 region that had viral fusion inhibitory activity at the micromolar level ${ }^{84,89,90}$. An NMR study has shown that in the pre-fusion intermediate state, the HR2 region forms a symmetric coiled-coil trimer, which has not been observed for other class I viral fusion proteins. The poor antiviral activity of anti-SARS-CoV peptides, compared with the anti-HIV peptides, could be attributed to the tendency of the SARS-CoV S protein HR2 region to form the trimeric coiled-coil. Replacement of the key residues in the HR2 peptide to reduce its ability to form the trimer, but increase its affinity of binding with the HR1 region, to form the six-helix bundle could lead to improvement of its antiviral efficacy. The peptidic antiviral drugs for SARS and other emerging infectious diseases with short incubation periods could have more advantages than the anti-HIV drug enfuvirtide, as enfuvirtide must be injected twice per day for the patient's lifetime. This results in an intolerable injection-site reaction and a high cost to patients, whereas a few injections of the peptidic drugs against SARS-CoV in the early stage of the acute phase could be enough to save patients' lives. One of the disadvantages of using HR2-based peptide inhibitors is the potential selection of escape mutants with altered host-range phenotypes ${ }^{91}$.

\section{mAbs that target the $\mathrm{S}$ protein}

Neutralizing mouse mAbs. Using rRBD and inactivated SARS-CoV as immunogens, we have successfully generated a panel of highly potent neutralizing mouse monoclonal antibodies (mAbs) that could block receptor binding and cross-neutralize infection by pseudoviruses that bore $S$ proteins of the representative human SARS-CoV strains that caused the 20022003 and 2003-2004 outbreaks (Tor2 and GD03T13) and palm civet SARS-CoV (SZ3) ${ }^{63,69,71,92}$. Mouse mAbs that target other fragments of the SARS-CoV S protein (for example, amino acids 1,143-1,157) could also effectively inhibit SARS-CoV infection ${ }^{56,93}$. These neutralizing mouse $\mathrm{mAbs}$ can be administered to patients with SARS for early and urgent treatment of SARS$\mathrm{CoV}$ infection', but cannot be repeatedly used owing to the risk of a human-anti-mouse antibody response. Such a response could rapidly clear the murine antibody from the blood, thus preventing the mouse antibodies from producing the desired therapeutic effect and causing the patient to have an allergic reaction ${ }^{94}$. Some antibodies against trimeric $\mathrm{S}$ protein have the potential to mediate Fc $\gamma$ RII-dependent entry into $\mathrm{B}$ cells in vitro and thereby cause antibody-dependent enhancement ${ }^{62}$.

Neutralizing human $m A$ bs. A range of neutralizing human mAbs have been generated from B cells of patients infected with SARS-CoV ${ }^{95,96}$ or from human immunoglobulin transgenic mice immunized with full-length SARS-CoV S protein ${ }^{97-99}$. These S-specific mAbs, such as 80R and CR3014, could block SARSCoV S protein binding with the ACE2 receptor and neutralize infection by human SARS-CoV strains Tor2 and HKU39849 and/or palm civet SARS-CoV strain SZ3 (REFS 32,100,101). mAbs m396 and S230.15 neutralize human SARS-CoV and/or pseudoviruses that bear S proteins of human SARS-CoV strains (Urbani, Tor2 and GD03) and palm civet SARS-CoV strains (SZ3 and SZ16) ${ }^{97}$. Human anti-S mAbs S109.8, S215.17, S227.14 and S230.15 cross-neutralize infection by a panel of recombinant SARS-CoV strains bearing variant $S$ proteins that are representative of human strains (GZ02, CUHK-W1 and Urbani) and zoonotic strains found in palm civet (HC/SZ/61/03) and raccoon $\operatorname{dog}(\mathrm{A} 031 \mathrm{G})^{99}$. Some human $\mathrm{mAbs}$, such as $80 \mathrm{R}^{32}, \mathrm{~m} 396$ (REF. 97), 201 and 68 (REF. 102), exhibit potent antiviral effects against homologous SARS$\mathrm{CoV}$ challenge in young-mouse replication models. However, others, such as S109.8, S227.14 and S230.15 (REF. 99), could induce broad protection against lethal homologous and heterologous SARS-CoV challenge in both young- and aged-mouse models, providing a strategy to minimize the emergence of $\mathrm{mAb}$ escape mutants.

\section{Antiviral compounds and small molecules}

Inhibitors of cathepsin L. Cathepsin L activates S protein-mediated membrane fusion by facilitating receptordependent and acid-dependent conformational changes in the S2 domain. This occurs in endosomes in which a low $\mathrm{pH}$ allows for optimal proteolytic activity $35,103,104$. Thus, cathepsin L inhibitors, such as E63c, E64d and MDL28170, can block viral entry or inhibit in vitro infection of SARS-CoV or SARS pseudoviruses ${ }^{103,105,106}$. These findings suggest that compounds which inhibit 
the activity of cathepsin L protease could be developed as therapeutics for the inhibition of SARS-CoV infection, but their in vivo antiviral activity should be further tested in animal models.

Other compounds and small molecules that target the $S$ protein. Several other compounds and small molecules that target the $\mathrm{S}$ protein have been reported. For example, amiodarone blocks the in vitro spread of SARS-CoV by inhibiting virus infection at a postendosomal level ${ }^{107}$. Yi et al. ${ }^{108}$ identified two small molecules, tetra-O-galloyl-beta-D-glucose (TGG) and luteolin, which have inhibitory activity, that blocked SARS-CoV or SARS pseudovirus entry into Vero E6 cells. Kao et al. ${ }^{109}$ identified 18 small molecules that targeted S protein-ACE2-mediated viral entry. One of these, VE607, exhibits potent inhibitory activity on SARS pseudovirus entry into ACE2-expressing $293 \mathrm{~T}$ cells. These reports suggest that the small molecules discussed above can function as effective antiviral inhibitors against $\mathrm{S}$ protein-mediated viral entry. However, further studies are needed to determine the in vivo efficacy of these antiviral agents in animal models and select optimal formulations to deliver effective concentrations of the drugs to the target tissues.

Gene targeting with small interfering RNA. RNA interference induced by a small interfering RNA (siRNA) has been successfully used recently as a specific and efficient method for silencing specific viral genes, interrupting protein synthesis and suppressing virus replication ${ }^{110,111}$. It has been demonstrated that siRNAs directed against $\mathrm{S}$ sequences of SARS-CoV inhibited SARS-CoV replication in virus-infected Vero E6 cells ${ }^{112}$. Several research groups ${ }^{113-117}$ reported that $\mathrm{S}$-specific siRNAs could reduce $\mathrm{S}$ protein expression by blocking $\mathrm{S}$ mRNA accumulation or reducing the number of copies of the viral genome in FRhK4 cells, indicating that $S$ gene expression in SARS-CoV-infected cells can be effectively silenced by $\mathrm{S}$-specific siRNAs. The in vivo study used a rhesus macaque model to indicate that siRNA duplexes (siSC2-5) that targeted the S protein and ORF1b of SARS-CoV could suppress SARS-like symptoms, inhibit virus replication in the monkey respiratory tract and protect lungs from acute damage ${ }^{118}$. The findings discussed above reveal the function of siRNA in the inhibition of SARS-CoV infection, replication and/or interruption of $S$ gene expression, raising hopes for the development of effective, novel antiviral agents against SARS-CoV.

A medication commonly used

to treat patients with irregular heart beats or cardiac

arrhythmias, including ventricular tachycardia and ventricular fibrillation.

Luteolin

A flavonoid extracted from

Chinese herbs, including

Prunella vulgaris and

Saussurea lappa Clarks. the SARS-CoV S protein may occur far upstream of the predicted fusion peptide (FIG. 2a). Unlike the S proteins of coronaviruses cleaved by furin-like proteases, the $\mathrm{S}$ protein of SARS-CoV can be cleaved by cathepsin $\mathrm{L}$ at position $\mathrm{T} 678$ or by trypsin at R667. In contrast to the entrance mechanism of HIV, SARS-CoV can enter cells from an acidic environment of the endosome ${ }^{119}$. Nevertheless, SARS-CoV can also enter the target cell surface, which is mediated by proteases on the cell surface through a non-endosomal-dependent pathway ${ }^{120}$.

The interaction between the SARS-CoV S protein and ACE2 is essential for SARS-CoV entry. The natural evolution of the epidemic SARS-CoV strains probably occurred over a long period, through the repeated transmission of viruses from animals to humans and from humans to animals, resulting in mutations in both the SARS-CoV S protein and ACE2, so that human and animal SARS-CoVs could enter cells that bore human or animal ACE2. Further understanding of the tropism of the virus and the mechanism of the SARS-CoV S protein in receptor binding and entry is therefore important for the development of anti-SARS-CoV therapeutics and vaccines.

As the major component for the development of vaccines against SARS, S protein, and especially the RBD, has been shown to induce highly potent neutralizing antibodies to block virus binding and membrane fusion and/or protective immunity against virus infection. Owing to the absence of human SARS cases in recent years, future SARS epidemics will probably originate from zoonotic transmission. SARS vaccines should therefore protect against not only human SARS-CoV strains, including those from early, middle and late phases of the epidemic, but also those of zoonotic origin. Although current vaccine candidates effectively neutralize SARS-CoV in young-animal replication models without clinical symptoms, they may not protect an elderly population against SARS-CoV infection. Thus, it is essential to test the vaccine candidates in robust lethal-challenge models using aged animals. Future vaccines should effectively protect both the young and the elderly populations from infection by either human or animal SARS-CoV strains that may cause future SARS epidemics.

Peptides and non-peptidic small molecules that target the functional domain of the SARS-CoV S protein, particularly the RBD in the S1 subunit and the HR2 region in the S2 subunit, are mainly virus entry inhibitors and can be further developed as anti-SARS-CoV therapeutics. To develop these molecules as effective and safe antiviral drugs for the treatment of SARS, the urgent task is to improve their potency. Mouse and human $\mathrm{mAbs}$ that target the $\mathrm{S}$ protein of SARS-CoV have shown potent inhibition and/or neutralization to homologous and heterologous SARS-CoV isolates and can be further developed as immunotherapeutics or passive immunization agents for therapy and prophylaxis of SARS-CoV infection. Future studies are needed to test the in vivo efficacy of these antiviral agents in animal models. 
Overall, the feasibility of using peptides and small molecules as anti-SARS therapeutics is partially limited by their low antiviral potency. Furthermore, the possibility of enhancing viral entry might restrict mAbs as immunotherapeutics for long-term use. It is likely, however, that $S$ protein-based vaccines will bear fruit in the near future, as they have been proven to induce long-term and potent neutralizing antibodies and/or protective immunity against SARS-CoV. But the in vivo efficacy of these vaccine candidates in elderly and lethal-challenge models, and their protection against zoonotic virus infection, should be determined before a clinical study is initiated. To take these factors into full consideration, a combination of different strategies with multiple vaccines and antiviral therapeutics may be needed to induce broad and cross protection against various virus strains, especially isolates that have mutated quickly. Early clinical studies that were based on such strategies have been carried out, but it is difficult to push the clinical trials of these candidate vaccines and therapeutics forwards owing to a lack of SARS-CoV-infected subjects and insufficient financial support. Thus, most big pharmaceutical companies have no interest in developing SARS vaccines and therapeutics because of the concern of profitability. However, studies on SARS will provide important information for designing novel strategies for prophylaxis and therapies of other newly emerging infections caused by enveloped viruses with class I fusion proteins.
1. Zhong, N. S. et al. Epidemiology and cause of severe acute respiratory syndrome (SARS) in Guangdong, People's Republic of China, in February, 2003. Lance 362, 1353-1358 (2003)

2. Kuiken, T. et al. Newly discovered coronavirus as the primary cause of severe acute respiratory syndrome. Lancet 362, 263-270 (2003).

3. Marra, M. A. et al. The genome sequence of the SARS associated coronavirus. Science $\mathbf{3 0 0}$, 1399-1404 (2003).

4. Peiris, J. S. et al. Coronavirus as a possible cause of severe acute respiratory syndrome. Lancet 361 , 1319-1325 (2003).

5. Rota, P. A. et al. Characterization of a novel coronavirus associated with severe acute respiratory syndrome. Science 300, 1394-1399 (2003). Together with References 3 and 4, this article provided one of the earliest views of the SARS-CoV genome.

6. Guan, Y. et al. Isolation and characterization of viruses related to the SARS coronavirus from animals in southern China. Science 302, 276-278 (2003). First demonstration of SARS-CoV animal transmission.

7. Li, W. et al. Bats are natural reservoirs of SARS-like coronaviruses Science 310, 676-679 (2005).

8. Lau, S. K. et al. Severe acute respiratory syndrome coronavirus-like virus in Chinese horseshoe bats. Proc. Natl Acad. Sci. USA 102, 14040-14045 (2005)

9. Skowronski, D. M. et al. Severe acute respiratory syndrome (SARS): a year in review. Annu. Rev. Med. 56, 357-381 (2005)

10. Che, X. Y. et al. A patient with asymptomatic severe acute respiratory syndrome (SARS) and antigenemia from the 2003-2004 community outbreak of SARS in Guangzhou, China. Clin. Infect. Dis. 43, e1-e5 (2006).

11. Fleck, F. SARS virus returns to China as scientists race to find effective vaccine. Bull. World Health Organ. 82, 152-153 (2004)

12. Liang, G. et al. Laboratory diagnosis of four recent sporadic cases of community-acquired SARS, Guangdong Province, China. Emerg. Infect. Dis. 10, 1774-1781 (2004).

13. Shi, Z. \& Hu, Z. A review of studies on animal reservoirs of the SARS coronavirus. Virus Res. 133 74-87 (2008).

14. Liang, W. N. et al. Severe acute respiratory syndrome - retrospect and lessons of 2004 outbreak in China. Biomed. Environ. Sci. 19, 445-451 (2006).

15. Normile, D. Infectious diseases. Mounting lab accidents raise SARS fears. Science 304, 659-661 (2004).

16. Orellana, C. Laboratory-acquired SARS raises worries on biosafety. Lancet Infect. Dis. 4, 64 (2004).

17. Mo, H. Y. et al. Evaluation by indirect immunofluorescent assay and enzyme linked immunosorbent assay of the dynamic changes of serum antibody responses against severe acute respiratory syndrome coronavirus. Chin. Med. J. 118 446-450 (2005)

18. Xu, X. \& Gao, X. Immunological responses against SARS-coronavirus infection in humans. Cell. Mol. Immunol. 1, 119-122 (2004).

19. Zhong, X. et al. B-cell responses in patients who have recovered from severe acute respiratory syndrome target a dominant site in the S2 domain of the surface spike glycoprotein. J. Virol. 79, 3401-3408 (2005).
20. Li, T. et al. Long-term persistence of robust antibody and cytotoxic T cell responses in recovered patients infected with SARS coronavirus. PLOS ONE 1, e24 (2006)

21. See, R. H. et al. Severe acute respiratory syndrome vaccine efficacy in ferrets: whole killed virus and adenovirus-vectored vaccines. J. Gen. Virol. 89, 2136-2146 (2008)

22. Dutta, N. K. et al. Search for potential target site of nucleocapsid gene for the design of an epitope-based SARS DNA vaccine. Immunol. Lett. 118, 65-71 (2008).

23. Jin, H. et al. Induction of Th1 type response by DNA vaccinations with $\mathrm{N}, \mathrm{M}$, and $\mathrm{E}$ genes against SARS$\mathrm{CoV}$ in mice. Biochem. Biophys. Res. Commun. 328 979-986 (2005)

24. Zhi, Y. et al. Identification of murine CD8 T cell epitopes in codon-optimized SARS-associated coronavirus spike protein. Virology 335, 34-45 (2005)

25. Buchholz, U. J. et al. Contributions of the structural proteins of severe acute respiratory syndrome coronavirus to protective immunity. Proc. Natl Acad. Sci. USA 101, 9804-9809 (2004).

26. Zakhartchouk, A. N. et al. Immunogenicity of a receptor-binding domain of SARS coronavirus spike protein in mice: implications for a subunit vaccine. Vaccine 25, 136-143 (2007)

27. Zhang, C. Y., Wei, J. F. \& He, S. H. Adaptive evolution of the spike gene of SARS coronavirus: changes in positively selected sites in different epidemic groups. BMC Microbiol. 6, 88 (2006).

28. Weissenhorn, W. et al. Structural basis for membran fusion by enveloped viruses. Mol. Membr. Biol. 16 3-9 (1999)

29. Li, F., Li, W., Farzan, M. \& Harrison, S. C. Structure of SARS coronavirus spike receptor-binding domain complexed with receptor. Science 309, 1864-1868 (2005).

30. Wong, S. K., Li, W., Moore, M. J., Choe, H. \& Farzan, M. A 193-amino acid fragment of the SARS coronavirus $\mathrm{S}$ protein efficiently binds angiotensinconverting enzyme 2. J. Biol. Chem. 279 3197-3201 (2004)

31. Sainz, B. Jr, Rausch, J. M., Gallaher, W. R., Garry, R. F. $\&$ Wimley, W. C. Identification and characterization of the putative fusion peptide of the severe acute respiratory syndrome-associated coronavirus spike protein. J. Virol. 79, 7195-7206 (2005).

32. Sui, J. et al. Evaluation of human monoclonal antibody 80R for immunoprophylaxis of severe acute respiratory syndrome by an animal study, epitope mapping, and analysis of spike variants. J. Virol. 79, 5900-5906 (2005)

33. Li, F. et al. Conformational states of the severe acute respiratory syndrome coronavirus spike protein ectodomain. J. Virol. 80, 6794-6800 (2006).

34. Du, L. et al. Cleavage of spike protein of SARS coronavirus by protease factor $\mathrm{Xa}$ is associated with viral infectivity. Biochem. Biophys. Res. Commun. 359 174-179 (2007)

35. Bosch, B. J., Bartelink, W. \& Rottier, P. J. Cathepsin L functionally cleaves the SARS-CoV class I fusion protein upstream of rather than adjacent to the fusion peptide. J. Virol. 82, 8887-8890 (2008).

36. Lai, L. et al. Quaternary structure, substrate selectivity and inhibitor design for SARS 3C-like proteinase. Curr. Pharm. Des. 12, 4555-4564 (2006).
37. $\mathrm{Li}, \mathrm{W}$. et al. Angiotensin-converting enzyme 2 is a functional receptor for the SARS coronavirus. Nature 426, 450-454 (2003). First demonstration that ACE2 is a functional receptor of SARS-CoV.

38. Xiao, X., Chakraborti, S., Dimitrov, A. S., Gramatikoff, K. \& Dimitrov, D. S. The SARS-CoV S glycoprotein: expression and functional characterization. Biochem. Biophys. Res. Commun 312, 1159-1164 (2003). Presents the first characterization of the fusogenic function of SARS-CoV.

39. Babcock, G. J., Esshaki, D. J., Thomas, W. D. Jr \& Ambrosino, D. M. Amino acids 270 to 510 of the severe acute respiratory syndrome coronavirus spike protein are required for interaction with receptor. J. Virol. 78, 4552-4560 (2004).

40. Prabakaran, P. et al. Structure of severe acute respiratory syndrome coronavirus receptor-binding domain complexed with neutralizing antibody. J. Biol. Chem. 281, 15829-15836 (2006)

41. Qu, X. X. et al. Identification of two critical amino acid residues of the severe acute respiratory syndrome coronavirus spike protein for its variation in zoonotic tropism transition via a double substitution strategy. J. Biol. Chem. 280, 29588-29595 (2005).

42. Li, W. et al. Receptor and viral determinants of SARS coronavirus adaptation to human ACE2. EMBO J. 24 1634-1643 (2005).

43. Sheahan, T., Rockx, B., Donaldson, E., Corti, D. \& Baric, R. Pathways of cross-species transmission of synthetically reconstructed zoonotic severe acute respiratory syndrome coronavirus. J. Virol. 82 8721-8732 (2008).

44. Holmes, K. V. SARS-associated coronavirus. N. Engl. J. Med. 348, 1948-1951 (2003).

45. Hofmann, H. et al. S protein of severe acute respiratory syndrome-associated coronavirus mediates entry into hepatoma cell lines and is targeted by neutralizing antibodies in infected patients. J. Virol. 78, 6134-6142 (2004)

46. Kuhn, J. H., Li, W. Choe, H. \& Farzan, M. Angiotensinconverting enzyme 2: a functional receptor for SARS coronavirus. Cell. Mol. Life Sci. 61, 2738-2743 (2004).

47. Prabakaran, P., Xiao, X \& Dimitrov, D. S. A model of the ACE2 structure and function as a SARS-CoV receptor. Biochem. Biophys. Res. Commun. 314, 235-241 (2004)

48. Zhang, Y., Zheng, N., Hao, P., Cao, Y. \& Zhong, Y. A molecular docking model of SARS-CoV S1 protein in complex with its receptor, human ACE2. Comput. Biol. Chem. 29, 254-257 (2005).

49. He, Y., Li, J. \& Jiang, S. A single amino acid substitution (R441A) in the receptor-binding domain of SARS coronavirus spike protein disrupts the antigenic structure and binding activity. Biochem. Biophys. Res. Commun. 344, 106-113 (2006).

50. Jeffers, S. A. et al. CD209L (L-SIGN) is a receptor for severe acute respiratory syndrome coronavirus. Proc. Natl Acad. Sci. USA 101, 15748-15753 (2004).

51. Yang, Z. Y. et al. pH-dependent entry of severe acute respiratory syndrome coronavirus is mediated by the spike glycoprotein and enhanced by dendritic cell transfer through DC-SIGN. J. Virol. 78, 5642-5650 (2004). 
52. Han, D. P., Lohani, M. \& Cho, M. W. Specific asparagine-linked glycosylation sites are critical for DC-SIGN- and L-SIGN-mediated severe acute respiratory syndrome coronavirus entry. J. Virol. $\mathbf{8 1}$ 12029-12039 (2007).

53. Liu, S. et al. Interaction between heptad repeat 1 and 2 regions in spike protein of SARS-associated coronavirus: implications for virus fusogenic mechanism and identification of fusion inhibitors. Lancet 363, 938-947 (2004).

The first published paper to show that peptides derived from the HR2 region of the SARS-CoV S protein could inhibit SARS-CoV infection.

54. Tripet, B. et al. Structural characterization of the SARS-coronavirus spike S fusion protein core. J. Biol. Chem. 279, 20836-20849 (2004).

55. Xu, Y. et al. Crystal structure of severe acute respiratory syndrome coronavirus spike protein fusion core. J. Biol. Chem. 279, 49414-49419 (2004).

56. Zhou, T. et al. An exposed domain in the severe acute respiratory syndrome coronavirus spike protein induces neutralizing antibodies. J. Virol. 78, 7217-7226 (2004).

57. Keng, C. T. et al. Amino acids 1055 to 1192 in the S2 region of severe acute respiratory syndrome coronavirus S protein induce neutralizing antibodies: implications for the development of vaccines and antiviral agents. J. Virol. 79, 3289-3296 (2005)

58. Bukreyev, A. et al. Mucosal immunisation of African green monkeys (Cercopithecus aethiops) with an attenuated parainfluenza virus expressing the SARS coronavirus spike protein for the prevention of SARS. Lancet 363, 2122-2127 (2004).

59. Yang, Z. Y. et al. A DNA vaccine induces SARS coronavirus neutralization and protective immunity in mice. Nature 428, 561-564 (2004).

60. Bisht, H. et al. Severe acute respiratory syndrome coronavirus spike protein expressed by attenuated vaccinia virus protectively immunizes mice. Proc. Natl Acad. Sci. USA 101, 6641-6646 (2004).

61. Chen, Z. et al. Recombinant modified vaccinia virus Ankara expressing the spike glycoprotein of severe acute respiratory syndrome coronavirus induces protective neutralizing antibodies primarily targeting the receptor binding region. J. Virol. 79, 2678-2688 (2005).

62. Kam, Y. W. et al. Antibodies against trimeric $\mathrm{S}$ glycoprotein protect hamsters against SARS-CoV challenge despite their capacity to mediate $\mathrm{F} c \gamma \mathrm{RII}-$ dependent entry into B cells in vitro. Vaccine $\mathbf{2 5}$, 729-740 (2007)

63. He, Y., Li, J., Heck, S., Lustigman, S. \& Jiang, S Antigenic and immunogenic characterization of recombinant baculovirus-expressed severe acute respiratory syndrome coronavirus spike protein: implication for vaccine design. J. Virol. $\mathbf{8 0}$ 5757-5767 (2006).

64. Czub, M., Weingartl, H., Czub, S., He, R. \& Cao, J. Evaluation of modified vaccinia virus Ankara based recombinant SARS vaccine in ferrets. Vaccine 23 2273-2279 (2005)

65. Weingartl, H. et al. Immunization with modified vaccinia virus Ankara-based recombinant vaccine against severe acute respiratory syndrome is associated with enhanced hepatitis in ferrets. $J$. Virol. 78, 12672-12676 (2004)

66. Bonavia, A., Zelus, B. D., Wentworth, D. E., Talbot, P. J. \& Holmes, K. V. Identification of a receptorbinding domain of the spike glycoprotein of human coronavirus HCoV-229E. J. Virol. 77, 2530-2538 (2003).

67. Kubo, H., Yamada, Y. K. \& Taguchi, F. Localization of neutralizing epitopes and the receptor-binding site within the amino-terminal 330 amino acids of the murine coronavirus spike protein. J. Virol. 68 , 5403-5410 (1994).

68. He, Y., Zhou, Y., Siddiqui, P. \& Jiang, S. Inactivated SARS-CoV vaccine elicits high titers of spike proteinspecific antibodies that block receptor binding and virus entry. Biochem. Biophys. Res. Commun. 325 445-452 (2004)

69. He, Y. et al. Identification of a critical neutralization determinant of severe acute respiratory syndrome (SARS)-associated coronavirus: importance for designing SARS vaccines. Virology 334, 74-82 (2005).

70. He, Y. et al. Receptor-binding domain of SARS-CoV spike protein induces highly potent neutralizing antibodies: implication for developing subunit vaccine Biochem. Biophys. Res. Commun. 324, 773-781 (2004).
The earliest demonstration that the RBD of SARS-CoV $S$ protein induces highly potent neutralizing antibodies against SARS-CoV infection

71. He, Y. et al. Cross-neutralization of human and palm civet severe acute respiratory syndrome coronaviruses by antibodies targeting the receptor-binding domain of spike protein. J. Immunol. 176, 6085-6092 (2006)

72. Du, L. et al. Receptor-binding domain of SARS-CoV spike protein induces long-term protective immunity in an animal model Vaccine 25, 2832-2838 (2007).

73. Du, L. et al. Priming with rAAV encoding RBD of SARS CoV S protein and boosting with RBD-specific peptides for $\mathrm{T}$ cell epitopes elevated humoral and cellular immune responses against SARS-CoV infection. Vaccine 26, 1644-1651 (2008).

74. Du, L. et al. Recombinant adeno-associated virus expressing the receptor-binding domain of severe acute respiratory syndrome coronavirus S protein elicits neutralizing antibodies: implication for developing SARS vaccines. Virology 353, 6-16 (2006).

75. Du, L. et al. Intranasal vaccination of recombinant adeno-associated virus encoding receptor-binding domain of severe acute respiratory syndrome coronavirus (SARS-CoV) spike protein induces strong mucosal immune responses and provides long-term protection against SARS-CoV infection. J. Immunol. 180, 948-956 (2008)

76. Qin, C. et al. An animal model of SARS produced by infection of Macaca mulatta with SARS coronavirus. J. Pathol. 206, 251-259 (2005).

77. He, Y. et al. Identification and characterization of novel neutralizing epitopes in the receptor-binding domain of SARS-CoV spike protein: revealing the critical antigenic determinants in inactivated SARS-CoV vaccine. Vaccine 24, 5498-5508 (2006)

78. Rockx, B. et al. Synthetic reconstruction of zoonotic and early human severe acute respiratory syndrome coronavirus isolates that produce fatal disease in aged mice. J. Virol. 81, 7410-7423 (2007). Description of lethal animal-challenge models that recapitulate the age-related SARS disease.

79. Roberts, A. et al. A mouse-adapted SARS-coronavirus causes disease and mortality in BALB/c mice. PLoS Pathog. 3, e5 (2007)

Description of a pathogenic model for young mice as an animal-challenge model for the evaluation of SARS vaccines.

80. Deming, D. et al. Vaccine efficacy in senescent mice challenged with recombinant SARS-CoV bearing epidemic and zoonotic spike variants. PLoS Med. 3, e525 (2006).

Description of aged-mouse models for SARS vaccine testing.

81. Vogel, L. N. et al. Utility of the aged BALB/c mouse model to demonstrate prevention and control strategies for severe acute respiratory syndrome coronavirus (SARS-CoV). Vaccine 25, 2173-2179 (2007).

82. $\mathrm{Hu}, \mathrm{H}$. et al. Screening and identification of linear B-cell epitopes and entry-blocking peptide of severe acute respiratory syndrome (SARS)-associated coronavirus using synthetic overlapping peptide library. J. Comb. Chem. 7, 648-656 (2005).

83. Han, D. P., Penn-Nicholson, A. \& Cho, M. W. Identification of critical determinants on ACE2 for SARS-CoV entry and development of a potent entry inhibitor. Virology 350,15-25 (2006).

84. Zheng, B. J. et al. Synthetic peptides outside the spike protein heptad repeat regions as potent inhibitors of SARS-associated coronavirus. Antivir. Ther. 10, 393-403 (2005)

85. Jiang, S., Lin, K., Strick, N. \& Neurath, A. R. HIV-1 inhibition by a peptide. Nature 365, 113 (1993).

86. Wild, C. T., Shugars, D. C., Greenwell, T. K., Mcdanal, C. B. \& Matthews, T. J. Peptides corresponding to a predictive alpha-helical domain of human immunodeficiency virus type 1 gp 41 are potent inhibitors of virus infection. Proc. Natl Acad. Sci. USA 91, 9770-9774 (1994).

87. Liu, S., Wu, S. \& Jiang, S. HIV entry inhibitors targeting gp 41: from polypeptides to small-molecule compounds. Curr. Pharm. Des. 13, 143-162 (2007).

88. Chan, D. C. \& Kim, P. S. HIV entry and its inhibition. Cell 93, 681-684 (1998)

89. Bosch, B. J. et al. Severe acute respiratory syndrome coronavirus (SARS-CoV) infection inhibition using spike protein heptad repeat-derived peptides. Proc. Natl Acad. Sci. USA 101, 8455-8460 (2004).
90. Yuan, K., et al. Suppression of SARS-CoV entry by peptides corresponding to heptad regions on spike glycoprotein. Biochem. Biophys. Res. Commun. 319, 746-752 (2004)

91 Mcroy, W. C. \& Baric, R. S. Amino acid substitutions in the $\mathrm{S} 2$ subunit of mouse hepatitis virus variant V51 encode determinants of host range expansion. J. Virol. 82, 1414-1424 (2008)

92. He, Y., Lu, H., Siddiqui, P., Zhou, Y. \& Jiang, S. Receptor-binding domain of severe acute respiratory syndrome coronavirus spike protein contains multiple conformation-dependent epitopes that induce highly potent neutralizing antibodies. J. Immunol. 174, 4908-4915 (2005).

93. Lai, S. C. et al. Characterization of neutralizing monoclonal antibodies recognizing a 15-residues epitope on the spike protein HR2 region of severe acute respiratory syndrome coronavirus (SARS-CoV). J. Biomed. Sci. 12, 711-727 (2005).

94. Welt, S. \& Ritter, G. Antibodies in the therapy of colon cancer. Semin. Oncol. 26, 683-690 (1999).

95. Nie, Y. et al. Neutralizing antibodies in patients with severe acute respiratory syndrome-associated coronavirus infection. J. Infect. Dis. 190, 1119-1126 (2004).

96. Traggiai, E. et al. An efficient method to make human monoclonal antibodies from memory B cells: potent neutralization of SARS coronavirus. Nature Med. 10 , 871-875 (2004)

97. Zhu, Z. et al. Potent cross-reactive neutralization of SARS coronavirus isolates by human monoclonal antibodies. Proc. Natl Acad. Sci. USA 104, 12123-12128 (2007).

98. Coughlin, M. et al. Generation and characterization of human monoclonal neutralizing antibodies with distinct binding and sequence features against SARS coronavirus using XenoMouse. Virology 361, 93-102 (2007).

99. Rockx, B. et al. Structural basis for potent crossneutralizing human monoclonal antibody protection against lethal human and zoonotic severe acute respiratory syndrome coronavirus challenge. J. Virol. 82, 3220-3235 (2008)

100. Sui, J. et al. Potent neutralization of severe acute respiratory syndrome (SARS) coronavirus by a human $\mathrm{mAb}$ to $\mathrm{S} 1$ protein that blocks receptor association. Proc. Natl Acad. Sci. USA 101, 2536-2541 (2004).

101. Van Den Brink, E. N. et al. Molecular and biological characterization of human monoclonal antibodies binding to the spike and nucleocapsid proteins of severe acute respiratory syndrome coronavirus. J. Virol. 79, 1635-1644 (2005)

102. Greenough, T. C. et al. Pneumonitis and multi-organ system disease in common marmosets (Callithrix jacchus) infected with the severe acute respiratory syndrome-associated coronavirus. Am. J. Pathol. 167 455-463 (2005)

103. Huang, I. C. et al. SARS coronavirus, but not human coronavirus NL63, utilizes cathepsin L to infect ACE2 expressing cells. J. Biol. Chem. 281, 3198-3203 (2006).

104. Huang, I. C. et al. SARS-CoV, but not HCoV-NL63, utilizes cathepsins to infect cells: viral entry. $A d v$. Exp. Med. Biol. 581, 335-338 (2006).

105. Simmons, G. et al. Inhibitors of cathepsin L prevent severe acute respiratory syndrome coronavirus entry. Proc. Natl Acad. Sci. USA 102, 11876-11881 (2005).

106. Simmons, G., Rennekamp, A. J. \& Bates, P. Proteolysis of SARS-associated coronavirus spike glycoprotein. Adv. Exp. Med. Biol. 581, 235-240 (2006).

107. Stadler, K. et al. Amiodarone alters late endosomes and inhibits SARS coronavirus infection at a postendosomal level. Am. J. Respir. Cell Mol. Biol. 39 142-149 (2008)

108. Yi, L. et al. Small molecules blocking the entry of severe acute respiratory syndrome coronavirus into host cells. J. Virol. 78, 11334-11339 (2004).

109. Kao, R. Y. et al. Identification of novel small-molecule inhibitors of severe acute respiratory syndromeassociated coronavirus by chemical genetics. Chem. Biol. 11, 1293-1299 (2004).

110. Li, T. et al. siRNA targeting the leader sequence of SARS-CoV inhibits virus replication. Gene Ther. 12, 751-761 (2005)

111. Gitlin, L., Karelsky, S. \& Andino, R. Short interfering RNA confers intracellular antiviral immunity in human cells. Nature 418, 430-434 (2002).

112. Wu, C. J., Huang, H. W., Liu, C. Y., Hong, C. F. \& Chan, Y. L. Inhibition of SARS-CoV replication by siRNA. Antiviral Res. 65, 45-48 (2005). 
113. Akerstrom, S., Mirazimi, A. \& Tan, Y. J. Inhibition of SARS-CoV replication cycle by small interference RNAs silencing specific SARS proteins, $7 \mathrm{a} / 7 \mathrm{~b}, 3 \mathrm{a} / 3 \mathrm{~b}$ and $\mathrm{S}$. Antiviral Res. 73, 219-227 (2007)

114. He, M. L. et al. Kinetics and synergistic effects of siRNAs targeting structural and replicase genes of SARS-associated coronavirus. FEBS Lett. $\mathbf{5 8 0}$ 2414-2420 (2006).

115. Zheng, B. J. et al. Prophylactic and therapeutic effects of small interfering RNA targeting SARS-coronavirus. Antivir. Ther. 9, 365-374 (2004).

116. Qin, Z. L. et al. Silencing of SARS-CoV spike gene by small interfering RNA in HEK $293 \mathrm{~T}$ cells. Biochem. Biophys. Res. Commun. 324, 1186-1193 (2004).

117. Zhang, Y. et al. Silencing SARS-CoV spike protein expression in cultured cells by RNA interference. FEBS Lett. 560, 141-146 (2004).

118. Li, B. J. et al. Using siRNA in prophylactic and therapeutic regimens against SARS coronavirus in rhesus macaque. Nature Med. 11, 944-951 (2005).

119. Simmons, G. et al. Characterization of severe acute respiratory syndrome-associated coronavirus (SARSCoV) spike glycoprotein-mediated viral entry. Proc. Natl Acad. Sci. USA 101, 4240-4245 (2004).

120. Matsuyama, S., Ujike, M., Morikawa, S., Tashiro, M. \& Taguchi, F. Protease-mediated enhancement of severe acute respiratory syndrome coronavirus infection. Proc. Natl Acad. Sci. USA 102, 12543-12547 (2005).

121. Qinfen, Z. et al. The life cycle of SARS coronavirus in Vero E6 cells. J. Med. Virol. 73, 332-337 (2004).

122. Guo, Y., Korteweg, C., Mcnutt, M. A. \& Gu, J. Pathogenetic mechanisms of severe acute respiratory syndrome. Virus Res. 133, 4-12 (2008).

123. Gu, J. \& Korteweg, C. Pathology and pathogenesis of severe acute respiratory syndrome. Am. J. Pathol. 170, 1136-1147 (2007).

124. Ding, Y. et al. Organ distribution of severe acute respiratory syndrome (SARS) associated coronavirus (SARS-CoV) in SARS patients: implications for pathogenesis and virus transmission pathways. J. Pathol. 203, 622-630 (2004)

125. Frieman, M., Heise, M. \& Baric, R. SARS coronavirus and innate immunity. Virus Res. 133, 101-112 (2008).

126. Weiss, S. R. \& Navas-Martin, S. Coronavirus pathogenesis and the emerging pathogen severe acute respiratory syndrome coronavirus. Microbiol. Mol. Biol. Rev. 69, 635-664 (2005)

127. Holmes, K. V. SARS coronavirus: a new challenge for prevention and therapy. J. Clin. Invest. 111 1605-1609 (2003).

128. Stertz, S. et al. The intracellular sites of early replication and budding of SARS-coronavirus. Virology 361, 304-315 (2007)

129. Inoue, Y. et al. Clathrin-dependent entry of severe acute respiratory syndrome coronavirus into target cells expressing ACE2 with the cytoplasmic tail deleted. J. Virol. 81, 8722-8729 (2007).

130. Hakansson-Mcreynolds, S., Jiang, S., Rong, L. \& Caffrey, M. Solution structure of the severe acute respiratory syndrome-coronavirus heptad repeat 2 domain in the prefusion state. J. Biol. Chem. 281 11965-11971 (2006)

131. Zhao, P. et al. DNA vaccine of SARS-CoV S gene induces antibody response in mice. Acta Biochim. Biophys. Sin. (Shanghai) 36, 37-41 (2004).

132. Wang, S. et al. Identification of two neutralizing regions on the severe acute respiratory syndrome coronavirus spike glycoprotein produced from the mammalian expression system. J. Virol. 79, 1906-1910 (2005).

133. Huang, J. et al. Priming with SARS-CoV S DNA and boosting with SARS-CoV S epitopes specific for $\mathrm{CD}^{+}$ and $\mathrm{CD} 88^{+} \mathrm{T}$ cells promote cellular immune responses. Vaccine 25, 6981-6991 (2007)

134. Liu, L. et al. Natural mutations in the receptor binding domain of spike glycoprotein determine the reactivity of cross-neutralization between palm civet coronavirus and severe acute respiratory syndrome coronavirus. J. Virol. 81, 4694-4700 (2007).

135. Taylor, D. R. Obstacles and advances in SARS vaccine development. Vaccine 24, 863-871 (2006).

136. Kliger, Y., Levanon, E. Y. \& Gerber, D. From genome to antivirals: SARS as a test tube. Drug Discov. Today 10, 345-352 (2005).

137. Wu, X. D. et al. The spike protein of severe acute respiratory syndrome (SARS) is cleaved in virus infected Vero-E6 cells. Cell Res. 14, 400-406 (2004).

138. Ujike, M. et al. Heptad repeat-derived peptides block protease-mediated direct entry from the cell surface of severe acute respiratory syndrome coronavirus but not entry via the endosomal pathway. J. Virol. 82, 588-592 (2008)

139. Yang, Z. Y. et al. Evasion of antibody neutralization in emerging severe acute respiratory syndrome coronaviruses. Proc Natl Acad Sci. USA 102 797-801 (2005)

140. Subbarao, K. et al. Prior infection and passive transfer of neutralizing antibody prevent replication of severe acute respiratory syndrome coronavirus in the respiratory tract of mice. J. Virol. 78, 3572-3577 (2004).

141. Mitsuki, Y. Y. et al. A single amino acid substitution in the $\mathrm{S} 1$ and $\mathrm{S} 2$ spike protein domains determines the neutralization escape phenotype of SARS-CoV. Microbes Infect. 10, 908-915 (2008).

142. Ter Meulen, J. et al. Human monoclonal antibody as prophylaxis for SARS coronavirus infection in ferrets. Lancet 363, 2139-2141 (2004).

143. Roberts, A. et al. Therapy with a severe acute respiratory syndrome-associated coronavirusneutralizing human monoclonal antibody reduces disease severity and viral burden in golden Syrian hamsters. J. Infect. Dis. 193, 685-692 (2006).

\section{Acknowledgements}

We thank all three anonymous reviewers for their constructive comments and informative suggestions. Our research was supported by the National Institutes of Health (NIH) of the United States (RO1 Al68002), by the Research Fund for the Control of Infectious Diseases, the Food and Health Bureau of the Hong Kong SAR Government, and by the National 973 Basic Research Program of China (2005CB523001).

\section{DATABASES}

Entrez Genome: http://www.ncbi.nlm.nih.gov/entrez/query.

fcgi?db=genome

HIV-1 $\mid$ MHV ISARS-CoV

UniProtKB: http://www.uniprot.org

ACE2 $|\underline{E}| \underline{M}|\underline{N}| \underline{S}$

FURTHER INFORMATION

Shibo Jiang's homepage:

http://www.nybc.org/research/research/index.

do? sid $0=7$ ssid $1=32$ \&page id $=31$ \&content id $=91$

WHO update 7: http://www.who.int/csr/don/2004 05 18a

en/index.html

WHO update 49: http://www.who.int/csr/sars/

archive/2003 05 07a/en/

ALL LINKS ARE ACTIVE IN THE ONLINE PDF 